\title{
A three-player game analysis on industrial environmental pollution control
}

\author{
Kexin $\mathrm{Hou}^{1, *}$ \\ ${ }^{1}$ Tianjin University of Technology, School of Management, 300384 Tianjin, China
}

\begin{abstract}
The environmental pollution of industrial enterprises has severely restricted the development of economy and society. In the face of serious industrial environmental pollution, this paper constructs a threeplayer game model including enterprises, government and the public, and conducts a balanced analysis on the interests of the three parties in enterprise environmental pollution control. The results show that the regulation effect of pollutant discharge punishment on industrial enterprises is better than that of pollution control subsidies, and the system with high fines and high subsidies will reduce the enthusiasm of enterprises to comply with regulations.
\end{abstract}

\section{Production}

Industrial pollution is one of the most difficult problems in the world. With the continuous advancement of industrialization, industrial enterprises uncontrollably cause pollution and damage to the environment in processing and utilizing scarce resources. The governments of various countries have introduced a series of environmental control policies and systems, which have aroused widespread concern of the public [1].

Many scholars have carried out studies on environmental pollution and treatment from different perspectives. Based on the hypothesis of "rational man", Fairchild used game theory and mathematical modeling to analyze the interaction between enterprises and the government in the process of environmental pollution regulation [2]. Lee found that the most important driving factors of environmental behavior of industrial enterprises are government participation and maturity of green supply chain [3]. Grigmar et al. clearly elaborated the game behavior between the government and enterprises in the implementation of environmental protection policies [4]. In addition to government environmental regulation, informal regulation of industrial enterprises' environmental behavior, such as public demand constraint lays an increasingly important role.

With the occurrence of community health issues, the public's perception of environmental risks and awareness of environmental protection are on the rise. Michael proposed that the public has linked the appeal for a better environment with their own interests, and then reacted in behavior to exert pressure on the government [5]. Dungumaro et al. discussed the positive role of public participation in ecological environmental protection through game analysis [6]. Umberto Sconfienza found that public participation could provide decision-makers with more abundant and diversified information to help them make better decisions [7].

Therefore, the government environmental regulation and the public demand constraint jointly affect the environmental behaviors of industrial enterprises. In this way, this paper will build a three-player game model of the government, enterprises and the public in the enterprise environmental pollution control.

\section{The Hypothesis and Establishment of The Three-Player Game Model}

This paper argues that whether industrial enterprises comply with environmental regulations is influenced by the regulatory pressure from both the government and the public, which forms a three-player game between the government, the public and enterprises. All the players of the game are "economic man", and their goals are to maximize their own economic interests.

In the presence of environmental regulations, enterprises may choose to obey environmental regulations to reduce industrial emissions, or may choose not to obey. If an enterprise complies with environmental regulations, on the one hand, the cost of meeting environmental protection requirements will increase by $C_{e}$. On the other hand, because the products are more environmentally friendly and can better meet the green demand of the market, the enterprise can raise the product price, so that the income will increase by $R_{e}$. However, if enterprises do not comply with environmental regulations, they may face fines $F_{e}$ from the government and losses $L_{e}$ from public exposure.

\footnotetext{
*Corresponding author: 17853145575@163.com
} 


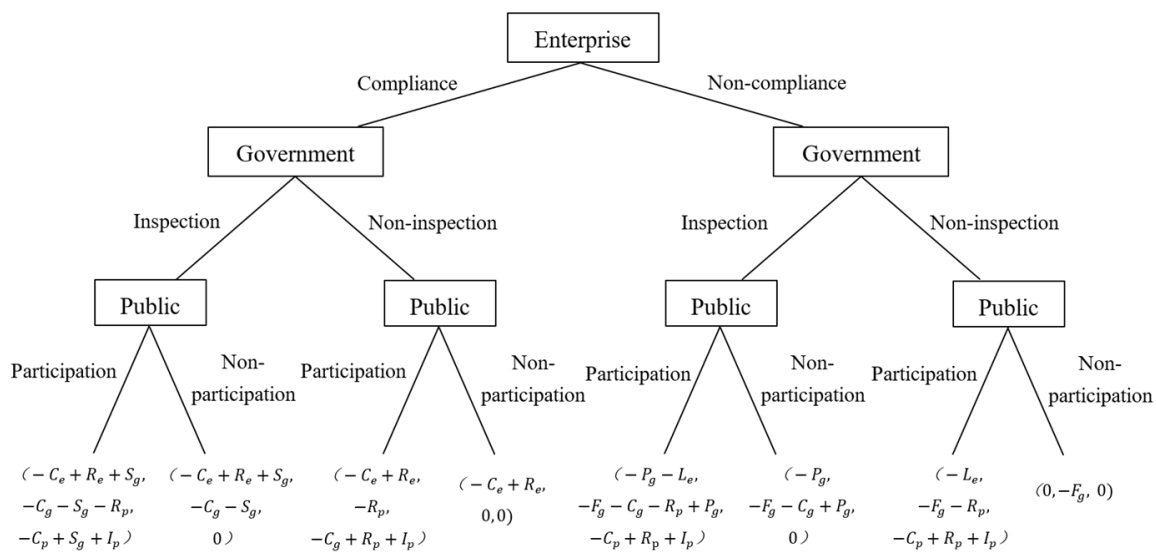

Fig. 1. Three-player game tree of government, public and enterprise

The government has the responsibility to manage enterprises and may choose to inspect whether the enterprises comply with environmental regulations, or not. If the government carries out inspections, it will give subsidies $S_{g}$ to companies that comply with regulations, and impose fines $P_{g}$ on those who don't, while generating inspection costs $C_{g}$. Conversely, if the government does not inspect the enterprises, it will have to pay $F_{g}$ for the disposal of the industrial pollution produced. Similarly, as an important social supervision force, the public also has two strategic choices: to supervise whether enterprises obey environmental regulations, or not. If the public participates in the supervision, on the one hand, it needs to pay the cost $C_{p}$, and on the other hand, it will obtain the government reward income $R_{p}$ and spiritual benefit $I_{p}$. The game relationship among the government, the public and enterprises is shown in Figure 1.

The game model explains the relationship among government, public and enterprise in the process of industrial environmental pollution control. Since most industrial enterprises have no strong awareness of environmental protection at present, the government tries to improve the current situation of industrial environmental pollution control through various means.

\section{Equilibrium Analysis of The Three- Player Game}

\subsection{Pure strategy Nash equilibrium analysis}

Through the equilibrium analysis of the game model, this paper obtains six possible results and corresponding conditions of the Pure strategy Nash equilibrium in this model, as shown in Table 1. Since the constant parameters are greater than zero, the strategy combination (enterprise compliance, government inspection, public participation) and (enterprise compliance, government inspection, public non-participation) does not exist. The results and conditions of the above pure strategy Nash equilibrium show that:
Table 1. Results of pure strategy Nash equilibrium

\begin{tabular}{|c|c|}
\hline Pure strategy combination & Conditions \\
\hline $\begin{array}{c}\text { Enterprise compliance, government } \\
\text { non-inspection, public participation }\end{array}$ & $R_{e}-C_{e}>-L_{e} ;$ \\
$R_{p}+I_{p}>C_{p}$ \\
\hline $\begin{array}{c}\text { Enterprise compliance, government } \\
\text { non-inspection, public non- } \\
\text { participation }\end{array}$ & $R_{e}-C_{e}>0 ;$ \\
$R_{p}+I_{p}<C_{p}$
\end{tabular}

The results show that only the combination of strategies (compliance, non-inspection, participation) and (compliance, non-inspection, non-participation) meet the development requirements. The condition for achieving these two equilibria is that the profit minus cost after compliance is greater than the loss after exposure or greater than zero. This requires enterprises to promote various means of pollution control, comply with environmental regulations, constantly improve revenue, and further reduce costs. If none of the conditions in Table 1 are true, the three-party game has no Nash equilibrium stable solution, then the three participants will adopt a mixed strategy. 


\subsection{Nash Equilibrium Analysis of Mixed Strategies}

In the absence of pure strategy Nash equilibrium, enterprises, governments and the public will adopt mixed strategies and adopt their pure strategies with certain probabilities. Assume that the enterprise chooses the strategy of "compliance" with a probability of $x$ and "non-compliance" with a probability of $1-x$. The government chooses "inspection" with a probability of $y$ and "non-inspection" with a probability of $1-y$. Similarly, we set a probability of $z$ for the public to choose "participation" and a probability of $1-z$ for "non-participation". Where $0 \leq x \leq 1,0 \leq y \leq 1,0 \leq$ $z \leq 1$. The expected earnings of the enterprise choosing "compliance" and "non-compliance" are respectively $U_{1}$ and $U_{2}$, then:

$$
\begin{gathered}
U_{1}=y\left[z\left(-C_{e}+R_{e}+S_{g}\right)+(1-z)\left(-C_{e}+R_{e}+S_{g}\right)\right] \\
+(1-y)\left[z\left(-C_{e}+R_{e}\right)\right. \\
\left.+(1-z)\left(-C_{e}+R_{e}\right)\right] \\
=y S_{g}+R_{e}-C_{e} \\
U_{2}=y\left[z\left(-P_{g}-L_{e}\right)+(1-z)\left(-P_{g}\right)\right]+(1- \\
y)\left[z\left(-L_{e}\right)+(1-z)\right]=-z L_{e}-y P_{g}
\end{gathered}
$$

The expected earnings of the government choosing "inspection" and "non-inspection" are respectively $V_{1}$ and $V_{2}$, then:

$$
\begin{gathered}
V_{1}=x\left[z\left(-C_{g}-S_{g}-I_{p}\right)+(1-z)\left(-C_{g}-S_{g}\right)\right] \\
+(1-x)\left[z\left(-F_{g}-C_{g}+R_{p}+P_{g}\right)\right. \\
\left.+(1-z)\left(-F_{g}-C_{g}+P_{g}\right)\right] \\
=x\left(F_{g}-P_{g}-S_{g}\right)+P_{g}-F_{g}-C_{g}-z R_{p} \\
V_{2}=x\left[z\left(-R_{p}\right)+(1-z)\right]+(1-x)\left[z\left(-F_{g}-R_{p}\right)+\right. \\
\left.(1-z)\left(-F_{g}\right)\right]=(x-1) F_{g}-z R_{p}
\end{gathered}
$$

The expected earnings of the public choosing "participation" and "non-participation" are respectively $W_{1}$ and $W_{2}$, then:

$$
\begin{gathered}
W_{1}=x\left[y\left(-C_{p}+R_{P}+I_{p}\right)+(1-y)\left(-C_{P}+R_{P}+I_{p}\right)\right]+ \\
(1-x)\left[\left(-C_{P}+R_{P}+I_{p}\right)\right]=-C_{p}+R_{P}+I_{p} \\
W_{2}=0
\end{gathered}
$$

For enterprises, the government and the public, when the expectations of different strategies are equal, the game reaches a stable equilibrium state, that is:

$$
\begin{gathered}
x=\frac{P_{g}-C_{g}}{P_{g}+S_{g}} \\
y=\frac{C_{e}-R_{e}-z L_{e}}{P_{g}+S_{g}} \\
z=\frac{C_{e}-R_{e}-y\left(P_{g}+S_{g}\right)}{L_{e}}
\end{gathered}
$$

Therefore, enterprises choose to comply with environmental regulations with a probability of $x=$ $\frac{P_{g}-C_{g}}{P_{g}+S_{g}}$, the government choose to inspect enterprises with a probability of $y=\frac{C_{e}-R_{e}-z L_{e}}{P_{g}+S_{g}}$, and the public choose to participate supervision $z=\frac{C_{e}-R_{e}-y\left(P_{g}+S_{g}\right)}{L_{e}}$.

\subsection{Economic Meaning of Equilibrium Solution}

In the three-player game model of government, public and enterprise, the optimal strategy combination is that the enterprise complies with environmental regulation, the government does not inspect, and the public does not participate. The following part focuses on the factors of the probability of enterprises compliance, government inspection and public participation, so as to draw management enlightenment.

According to Equation (7), on the other hand, $x$ is an increasing function of $P_{g}$, that is, the probability of enterprises complying with environmental regulations increases with the increase of government fines. On the other hand, $x$ is a minus function of $P_{g}$ and $S_{g}$, that is, the probability of compliance with environmental regulations decreases with the increase of government inspection costs and government subsidies.

Equation (8) shows that $y$ is an increasing function of $C_{e}$, that is, the probability of government inspection decreases with the increase of the cost of compliance with environmental regulations. Meanwhile, $y$ is also the minus function of $R_{e}, S_{e}, S_{g}$ and $P_{g}$, that is, the more profits an enterprise obtains after compliance with environmental regulations, the more they will take the initiative to control environmental pollution according to regulatory requirements.

Finally, Equation (9) indicates that $z$ is an increasing function of $C_{e}$, that is, the greater the cost of compliance, the less the initiative of compliance regulation. Simultaneously, $z$ is the minus function of $R_{e}, L_{e}, S_{g}$ and $P_{g}$, that is, the probability of public participation decreases with the increase of corporate profits, government subsidies, government fines, and losses of enterprises after exposure.

\section{Conclusions and Suggestions}

\subsection{Conclusions}

This paper establishes a three-player game model of government, public and enterprise in industrial pollution control. In this model, the optimal strategy combination is (enterprises compliance, government non-inspection, public non-participation), that is, the larger $x$ is, the better, while the smaller $y$ and $z$ are, the better. The specific conclusions are as follows:

First, government fines and subsidies are the main factors that affect enterprise' compliance, and government fines have a better regulation effect on enterprises than subsidies.

Second, the main factors affecting the probability of government inspection are enterprise cost, enterprise income and public participation.

Third, the main factors affecting the probability of public participation are enterprise cost, enterprise income and government inspection intensity.

\subsection{Policy Suggestions}

Based on the above conclusions, this paper puts forward the following policy suggestions for the government to implement effective environmental regulation.

On the one hand, consumers and the public should strengthen the publicity of green consumption awareness and environmental protection awareness, improve the 
preference of consumers and the public for green environmental protection products, so as to increase the demand for green environmental protection products from the market source and increase the profits of enterprises.

On the other hand, a reasonable punishment and reward mechanism should be established to improve the supervision efficiency of the government. The setting of fines should be based on the inspection cost, which is higher than the inspection cost. Only in this way can the inspection of enterprises be truly effective.

\section{Reference}

1. Yang, C.H., Tseng Y.H., and Chen C.P., Environmental Regulations, Induced R\&D, and Productivity: Evidence from Taiwan's Manufacturing Industries, Resour. Energy Econ. 34, 4 (2012)

2. Fairchild R.J., The manufacturing sector's environmental motives: a game-theoretic analysis, J. Bus. Ethics. 79, 3 (2008)

3. Lee S.Y., Drivers for the participation of small and medium-sized suppliers in green supply chain initiatives, Supply Chain Manag. 13, 3 (2008)

4. Gregmar I. Galinato, Hayley H., and Chouina R.D., Strategic interaction and institutional quality determinants of environmental regulations, Resour. Energy Econ. 53 (2018)

5. Michael A.B., Dennis A.R., Proactive corporate environmental management: A new industrial revolution, AMJ. 12, 2 (1998)

6. Dungumaro E.W., Madulu N.F., Public participation in integrated water resources management: the case of Tanzania, Phys. Chem. Earth. 28, 20 (2003)

7. Umberto S., The narrative of public participation in environmental governance and its normative presuppositions, RECIEL. 24, 2 (2015) 